\section{AB0392 RHEUMATOID ARTHRITIS AND RISK OF INCIDENT CHRONIC KIDNEY DISEASE: A SYSTEMATIC REVIEW AND META-ANALYSIS OF COHORT STUDIES}

P. Ungprasert ${ }^{1}$, S. Raksasuk ${ }^{2} .{ }^{1}$ Research and development, ${ }^{2}$ Medicine, Faculty of Medicine Siriraj Hospital, Mahidol University, Bangkok, Thailand

Background: Patients with rheumatoid arthritis (RA) may have a higher risk of developing chronic kidney disease (CKD) compared with general population. However, the data on this risk are limited and not well-characterised.

Objectives: This systematic review and meta-analysis aimed to comprehensively investigate the risk of incident CKD among patients with RA by reviewing all available studies.

Methods: A systematic review was performed using MEDLINE and EMBASE database from inception to December 2017 to identify all cohort studies (either retrospective or prospective) that compared the risk of incident CKD in patients with RA versus individuals without RA. Adjusted point estimates were extracted from individual studies and the pooled risk ratio and $95 \%$ confidence interval $(\mathrm{Cl})$ were calculated using random-effect, generic inverse-variance method of DerSimonian and Laird. Visualisation of funnel plot was used for evaluation for publication bias. Results: A total of 4 retrospective cohort studies with 1,627,981 participants were included. The risk of incident CKD was significantly increased among patients with RA with the pooled risk ratio of $1.52(95 \% \mathrm{Cl}, 1.28-1.80)$. The statistical heterogeneity of this study was high with an $\mathrm{I}^{2}$ of $82 \%$. The forest plot of this systematic review and meta-analysis is shown as figure 1 . The funnel plot was relatively symmetric and, thus, did not suggest the presence of publication bias in favour of positive studies.

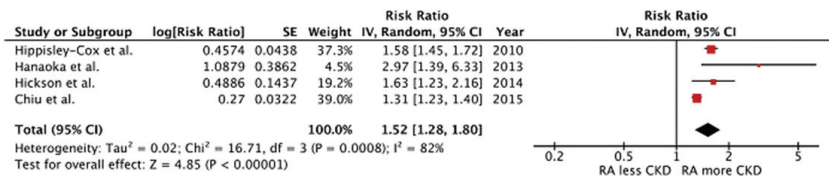

Abstract AB0392 - Figure 1. Forest plot of the meta-analysis on the risk of CKD among patients with RA

Abbreviation: SE, standard error; IV, inverse variance; CI, confidence interval, RA, rheumatoid arthritis; CKD, chronic kidney disease

Disclosure of Interest: None declared

DOI: 10.1136/annrheumdis-2018-eular.6792

\section{AB0393 ELECTROCARDIOGRAPHIC DISTURBANCES IN PATIENTS WITH RHEUMATOID ARTHRITIS USING ANTIMALARIAL DRUGS}

P. Rodriguez Henriquez ${ }^{1}$, F.J. Reyes-Muciño², L.M. Amezcua-Guerra ${ }^{3}$.

${ }^{1}$ Rheumatology; ${ }^{2}$ Internal Medicine, Hospital General Dr. Manuel Gea González;

${ }^{3}$ Immunology, Instituto Nacional de Cardiologia Ignacio Chavez, Mexico, Mexico

Background: Cardiac involvement is present in $7 \%$ to $35 \%$ of patients with rheumatoid arthritis (RA). Anecdotal case series have associated the use of antimalarial drugs with the presence of electrocardiographic disturbances in patients with RA

Objectives: To assess whether the use of antimalarial drugs is associated with the presence of electrocardiographic abnormalities in RA patients. The main clinical associations were also evaluated

Methods: A single-centre, case-control (1:1 proportion) medical chart review study was performed. A total of 144 patients with RA (ACR/EULAR 2010 criteria) were studied, and grouped as follows: 72 with a history of antimalarial drug use (case) and 72 who never used antimalarial drugs (control). We excluded individu als with a history of ischaemic heart disease or an already diagnosed disturbance of the cardiac rhythm/conduction.

Results: A total of 37 cases of electrocardiographic disturbances were found in patients receiving antimalarials (51\%), but only 18 cases $(25 \%)$ in the control group ( $p=0.001)$, giving an odds ratio (OR) of $3.17(95 \% \mathrm{Cl}, 1.57$ to 6.42$)$.

Rhythm disturbances observed in the antimalarial group were: left anterior branch hemiblock ( $n=12,32.4 \%)$, right branch block ( $n=10 ; 27.02 \%)$, 1st degree AV block $(n=5 ; 13.5 \%)$, bifascicular block $(n=4 ; 10.8 \%)$, posterior hemiblock of the left branch $(n=3 ; 8.1 \%)$, incomplete left bundle branch block $(n=2,5.4 \%)$, and left bundle branch block $(n=1,2.7 \%)$. Right bundle branch block was the only statistically significant conduction disorder $(27.02 \%$ vs $5.5 \%$ with p value of 0.004 [OR 11.45 1.43-92]).
The average dose of hydroxychloroquine was $3.02 \pm 0.41 \mathrm{mg} / \mathrm{kg}$, while the dose of chloroquine was $2.23 \pm 0.13 \mathrm{mg} / \mathrm{kg}$ ). A history of prednisone consumption also was associated with an increased risk to present an electrical cardiac disturbance ( $p=0.005$; OR 9.73, from 2.00 to 47.32 ).

Abstract AB0393 - Table 1

\begin{tabular}{lcccc}
\hline Outcomes & $\begin{array}{c}\text { Antimalaric } \\
(\mathrm{n}=72)\end{array}$ & $\begin{array}{c}\text { No Antimalaric } \\
(\mathrm{n}=72)\end{array}$ & $\mathrm{p}$ & $\begin{array}{c}\text { OR (IC } \\
95 \%)\end{array}$ \\
\hline $\begin{array}{l}\text { Cardiac conduction } \\
\text { electrocardiographic abnormalities }\end{array}$ & 37 & 18 & $\mathbf{0 . 0 0 1}$ & $\begin{array}{c}3.17(1.57- \\
6.42)\end{array}$ \\
1st Degree AV Blocking & 5 & 1 & 0.095 & $\begin{array}{c}5.3(0.6- \\
46.54)\end{array}$ \\
Left Branch Block & 1 & 5 & 0.095 & $\begin{array}{c}0.19(0.02- \\
1.66)\end{array}$ \\
Right Branch Lock & 10 & 1 & 0.004 & 11.45 \\
IBRB & 0 & & & $(1.43-92)$ \\
IBLB & 2 & 1 & 0.315 & - \\
AHLB & 12 & & 0.559 & $2.03(0.18-$ \\
& & 5 & 0.070 & $2.68(0.88)$ \\
PHLB & 3 & & & $8.05)$ \\
Bifascicular block & 4 & 0 & 0.080 & - \\
& & 4 & 1.000 & $1(0.24-$ \\
& & & & $4.16)$ \\
\hline
\end{tabular}

Conclusions: In this study, the use of antimalarial drugs was associated with an increased risk to present disturbances of the cardiac rhythm/conduction in patients with established RA.

\section{REFERENCES}

[1] Seferović PM, et al. Cardiac arrhythmias and conduction disturbances in autoimmune rheumatic diseases. Rheumatology (Oxford) 2006;45:iv39-42.

[2] Coskun S, et al. Cardiac involvement in patients with rheumatoid arthritis Journal of Rheumatology 2005;8:23-31.

[3] Costedoat-Chalumeau $\mathrm{N}$, et al. Heart conduction disorders related to antimalarials toxicity: an analysis of electrocardiograms in 85 patients treated with hydroxychloroquine for connective tissue diseases. Rheumatology 2007;46:808-810.

Disclosure of Interest: None declared DOI: 10.1136/annrheumdis-2018-eular.5668

\section{AB0394 OBSERVATIONAL STUDY OF THE INCIDENCE OF CARDIOVASCULAR EVENTS AND ASSOCIATED COMORBIDITIES IN A COHORT OF PATIENTS WITH RECENT ONSET RHEUMATOID ARTHRITIS}

R. Ortega Castro ${ }^{1}$, R. Jimenez-Gasco ${ }^{1}$, A.M. Cabezas-Lucena ${ }^{2}$, J. Calvo Gutiérrez $^{1}$, M.C. Castro-Villegas ${ }^{1}$, M. Romero-Gómez ${ }^{1}$, A. Escudero-Contreras ${ }^{1}$, E. Collantes-Estévez ${ }^{1}$, P. Font-Ugalde ${ }^{1}$. ${ }^{1}$ Rheumatology, Reina Sofía University Hospital/IMIBIC/University of Cordoba; ${ }^{2}$ Rheumatology, University of Cordoba, Córdoba, Spain

Background: Rheumatoid arthritis (RA) is a systemic autoimmune disease whose main characteristic is persistent joint inflammation that results in joint damage and loss of function. and can involve other tissues and organs (extra-articular manifestations). ${ }^{12}$ RA is associated with a high risk of morbidity and premature death secondary to the earlier development of cardiovascular, lung diseases and malignancy, being cardiovascular disease secondary to accelerated atherosclerosis the main cause of morbidity and mortality in these patients. ${ }^{34}$

Objectives: Main objective: To calculate the incidence of comorbidities and CV events in patients with recent onset RA. Secondary objectives:-To determine the clinical disease features according to baseline RA profile. To analyse the relationship between CV event and the different variables. To describe classic CV risk factors evolution throughout the follow-up.

Methods: We conducted a retrospective longitudinal observational study of 70 patients with recent onset RA according to ACR/EULAR 2010 or ACR 1987 criteria, at 5 years of follow-up.A descriptive study of the variables was carried out. For the bivariate analysis, the Chi-square test was used for the qualitative variables and the Mann Whitney $U$ test for the independent quantitative ones. For the paired data, the McNemar test was used for the qualitative variables and T Student for the quantitative ones. A logistic regression model was used to associate the main variable with the rest of the variables. Finally, the analysis of survival and regression of COX was carried out. All the contrasts were bilateral and were considered significant when $\mathrm{p}<0.05$ The statistical analysis was performed using SPSSV17. Results: The incidence of CV event was $18.57 \%$ (31\% acute myocardial infarction). During follow-up, an improvement in inflammatory and quality of life 
parameters (DAS28, ESR, CRP and HAQ) was observed $(p<0.05)$. Likewise, the $\%$ of hypertensive and dyslipidemic patients increased during follow up $(p<0.05)$, while the levels of cholesterol, triglycerides, glucose and diabetic patients remained similar. The presence of $\mathrm{CV}$ event was related to high levels of ESR, male sex and hypertension, $(p<0.05)$.

Conclusions:

- The incidence of cardiovascular event in our recent onset RA cohort resembles that previously described in the literature, with the majority occurring during the first 5 years of follow-up.

- The development of hypertension and dyslipidemia occurs mainly during the first 5 years of follow-up.

- The presence of a cardiovascular event was related to male sex, high blood pressure and high ESR levels.

\section{REFERENCES:}

[1] Mclnnes IB, Schett G. The Pathogenesis of Rheumatoid Arthritis. N Engl J Med 2011;365(23):2205-19.

[2] Mielants H, Van den Bosch F. Extra-articular manifestations. Clin Exp Rheumatology 2009;27(Suppl 55):S56-S61.

[3] Nurmohamed MT. Cardiovascular risk in rheumatoid arthritis. Autoimmunity Reviews 2009;8:663-7.

[4] del Rincón ID, Williams K, Stern MP, Freeman GL, Escalante A. High incidence of cardiovascular events in a rheumatoid arthritis cohort not explained by traditional cardiac risk factors. Arthritis Rheum 2001;44 (12):2737-45.

Disclosure of Interest: None declared

DOI: 10.1136/annrheumdis-2018-eular.3140

\section{AB0395 CORRELATION BETWEEN CARDIOVASCULAR RISK CALCULATORS IN A COHORT OF PATIENTS WITH RHEUMATOID ARTHRITIS}

R. Castellanos-Moreira, S.C. Rodriguez-Garcia, S. Mandelikova, V. Ruiz-Esquide, B. Frade-Sosa, A.B. Azuaga-Piñango, S.D.C. Rodriguez-Garcia, N. Sapena, C. Gonzalez-Delaurens, O. Camacho, J. Ramírez, M.V. Hernández, A. Cuervo, J. A. Gómez-Puerta, J.D. Cañete, R. Sanmarti. Rheumatology, Hospital Clinic de Barcelona, Barcelona, Spain

Background: EULAR recommends for patients with rheumatoid arthritis (RA) a cardiovascular (CV) risk assessment at least once every five years. Several risk calculators are available but most of them are based on data from general population, so they may underestimate the risk of RA patients. To obtain a more accurate estimation they should be adapted for RA by a 1.5 multiplication factor, unless the instrument includes RA as a variable. To date, there are no studies analysing the concordance and correlation between different $\mathrm{CV}$ risk calculators in spanish population.

Objectives: To analyse concordance and correlation of $\mathrm{CV}$ risk calculated using different tools and to determine the proportion of $\mathrm{CV}$ risk factors in a cohort of patients with RA.

Methods: We performed a cross-sectional study including patients with RA according to ACR/EULAR 2010 criteria, treated in a tertiary hospital. Individuals with previous $\mathrm{CV}$ events, diabetes and chronic kidney disease were excluded.

Ten-year CV risk was obtained with the following calculators: Framingham-body mass index (FRS-BMI), Framingham-lipids (FRS-L), SCORE CV risk calculator (SCORE) and the Expanded CV Risk Prediction Score for RA (ERS-RA). A 1.5 multiplying factor was used to adapt the results for RA patients in those which didn't include it in their models. CV risk was categorised as low or high using $10 \%$ as a cut-off for FRS-BMI and FRS-L and $5 \%$ for SCORE y ERS-RA. Correlation was evaluated using Spearman correlation coefficient (Rho) and concordance with weighted kappa.

Results: We included 88 patients ( 18 male), $87.5 \%$ Caucasian, mean age 56.9 \pm 10.6 years, mean disease duration $5.8 \pm 3.3$ years. $67 \%$ and $76 \%$ had positive RF and ACPA respectively and $15 \%$ presented extra-articular manifestations (rheumatoid nodules, interstitial lung disease, pleuropericarditis). Regarding CV risk factors: $14.8 \%$ were active smokers, $60.2 \%$ were overweight or obese, $25 \%$ had hypertension, $47.8 \%$ had dyslipidemia.

The median CV risk predicted at 10 years was 15\% (1.5-70.20) for FRS-IMC, $11.8 \%(1.2-54.0)$ for FRS-L, $1.5 \%(1.1-16.5)$ for SCORE and 6\% (0.6-27.8) for ERS-AR. 64 patients were categorised as low risk and 22 as high risk for ERSAR. No significant differences were observed in the means of risk obtained by the different calculators or in the risk categories according to ERS-RA when stratified by disease duration (more or less than 5 years).

For the correlation between ERS-RA and FRS-BMI, FRS-L and SCORE, Spearman's Rho coefficients were $0.84,0.79$ and 0.80 . $(p<0.005)$.
For the concordance between ERS-RA vs FRS-BMI a weighted $\kappa=0.29$ $\left(\mathrm{Cl}_{95} 0.15-0.42\right)$ was obtained. For ERS-AR vs FRS-L, $\kappa=0.34\left(\mathrm{Cl}_{95}: 0.19-0.50\right)$ and for ERS-AR vs SCORE, $\kappa=0.70\left(\mathrm{Cl}_{95}\right.$ : 0.52-0.87).

Conclusions: A strong correlation was observed between the $\mathrm{CV}$ risk calculators evaluated and good agreement only between ERS-AR and SCORE. Additionally, overweight, obesity and dyslipidemia were the most prevalent comorbidities.

Disclosure of Interest: None declared

DOI: 10.1136/annrheumdis-2018-eular.7044

\section{AB0396 RELATIONSHIP BETWEEN PATIENT GLOBAL ASSESSMENT AND PAIN ASSESSMENT IN THE DISEASE ACTIVITY INDEXES IN RHEUMATOID ARTHRITIS, AND ITS CORRESPONDENCE WITH SONOGRAPHIC ALTERATIONS}

R. Menor Almagro, R.M. Martínez, E.M. Rubio, M.M. Fernández. Rheumatology, Hospital Universitario Virgen del Rocío, Sevilla, Spain

Background: Disease activity indexes in rheumatoid arthritis (RA) provide information of different parameters in a single value. It is very useful in the evaluation of the disease activity and its progression. The subjective component of these indexes can modify the index final value.

Objectives: The aim of our study was to describe the relation between the patien global assessment (PGA) and pain assessment (PA) with the sonographic alterations in AR

Methods: Transversal study describing the ultrasonographic changes and disease activity indexes in AR. We included patients with RA according to ACR EULAR classification criteria. They were sent by their usual clinician, in random selection. They were reviewed in the same day by a rheumatologist and blind sonographer. PGA, PA, HAQ, tender and swollen joint count, CDAI, SDAI and DAS28 were evaluated. The ultrasound were realyzed by grey scale and doppler in 12 joints (wrists, second to fifth MCF and fifth bilateral MTF).

Results: A total of 48 patients had PGA $<50$ and $37 \mathrm{PGA} \geq 50$. The mean age was $53.2 \pm 11.7$ for group 1 and $56.5 \pm 10.2$ for group 2 , women $64.6 \%$ and $83.8 \%$ respectively. The positive rheumatoid factor resulted in $72.9 \%$ vs $73 \%$. The evolution of the disease in months presented a median of 96 (47.2-132.7) vs 108 [48138], $p=0.564$. The Body Mass Index in the groups was 26.6 (23.5-29.7) and 26.0 $(22.8-30.0), p=0.647$, and the tobacco consumption of 11 patients group 1 and 12 in group $2(p=0.397)$. No significant difference was found in the treatment at the time of the evaluation with methotrexate, median of $10(0-15)$ vs $7.5(0-15)$ $\mathrm{p}=0.350$, or corticosteroids $1.4(0-2,3)$ vs $2.5(0-4.5), p=0.05 .23$ patients in the group 1 and 19 in the group 2 were in biological therapy. The results referring to the patient's assessment of their disease, acute-phase reactants, clinical examination, ultrasound and disease activity indexes are presented in table 1

Abstract AB0396 - Table 1

\begin{tabular}{lccc}
\hline & $\begin{array}{c}\text { Group 1 } \\
(\mathrm{PGA}<50)\end{array}$ & $\begin{array}{c}\text { Group 2 } \\
(\mathrm{PGA}>50)\end{array}$ & $\begin{array}{c}\mathrm{P} \\
\text { value }\end{array}$ \\
\hline ESR: median (p25-p75) & $9(4,2-17)$ & $8(4,5-16)$ & 0578 \\
CRP: median (p25-p75) & $2,4(1,02-4,7)$ & $5(1-5,7)$ & 0996 \\
DAS 28 (CRP) & $2,1 \pm 0,97$ & $3,37 \pm 1,19$ & 0000 \\
DAS 28 (ESR) & $2,6 \pm 0,72$ & $3,25 \pm 0,92$ & 0000 \\
Pain assessment, 100 mm VAS: median & $20(0-40)$ & $70(50-80)$ & 0000 \\
(p25-p75) & & & \\
HAQ: average \pm DE & $0,8 \pm 0,14$ & $2,27 \pm 0,18$ & 0000 \\
Tender joint count: median (p25-p75) & $0(0-2)$ & $2(0-3)$ & 0001 \\
Swollen joint count: median (p25-p75) & $0(0-1)$ & $1(0-3)$ & 0090 \\
CDAl: median (p25-75) & $5(1-8,8)$ & $13(9,4-17,4)$ & 0000 \\
SDAl: average $\pm D E$ & $8,69 \pm 5,82$ & $17,67 \pm 6,49$ & 0000 \\
Synovitis in grey scale: median (p25-p75) & $1(0-3)$ & $2(0-4)$ & 0159 \\
Synovitis in doppler: median (p25-p75) & $0(0-1)$ & $1(0-2,7)$ & 0231 \\
\hline
\end{tabular}

Conclusions: Disease activity indexes in AR have been established as a very useful measure, both in the homogenization of the results obtained in the research and in the daily clinical practice. In our study, we observed the modification in the values of disease activity indexes due to PGA and PA, even those in which its contribution is less decisive than other parameters, as it happens in the DAS 28

Those variables no relationated in their value with the patient assessment of his disease status did not show statistical significance between the groups. The patients' valuation about activity of their AR and the modification of the indexes in which it participates in our study were not concordant with the echographic alterations found in grey scale and doppler echo.

Disclosure of Interest: None declared

DOI: 10.1136/annrheumdis-2018-eular.7080 